\title{
HUBUNGAN DUKUNGAN KELUARGA DENGAN KEMANDIRIAN LANSIA DI POSBINDU CEMPAKA WILAYAH KERJA PUSKESMAS PUGUK KABUPATEN SELUMA
}

\section{The Relationship between Family Support with Independence of Elderly in Posbindu Cempaka Working Area of Puguk Public Health Center Seluma Regency}

\author{
Wedi Lufty $^{1}$, Nurul Khairani ${ }^{1}$, Effendi ${ }^{1}$ \\ ${ }^{1}$ Prodi Kesehatan Masyarakat STIKES Tri Mandiri Sakti Bengkulu \\ Email : wedi.bkl12@gmail.com
}

\begin{abstract}
ABSTRAK
Peningkatan jumlah lansia yang terjadi kini, menimbulkan berbagai masalah kesehatan pada lansia. Adapun permasalahan yang terkait dengan lanjut usia antara lain pengaruh proses menua yang dapat menimbulkan berbagai masalah terhadap perubahan fisik, psikologi maupun sosial. Secara umum perubahan fisik akan berdampak pada penurunan aktivitas sehari-hari yang dijalani oleh lansia. Perubahan fisik tersebut akan mempengaruhi tingkat kemandirian lansia dalam beraktivitas. Tujuan penelitian ini adalah untuk mengetahui hubungan dukungan keluarga dengan kemandirian lansia di Posbindu Cempaka wilayah kerja Puskesmas Puguk Kabupaten Seluma. Penelitian ini adalah penelitian Survei Analitik dengan desain Cross Sectional. Populasi dalam penelitian ini adalah seluruh lansia di Posbindu Cempaka Kelurahan Puguk Kabupaten Seluma bulan Juni tahun 2019 berjumlah 35 lansia. Sampel dalam penelitian ini adalah seluruh lansia yang berkunjung di Posbindu Cempaka wilayah kerja Puskesmas Puguk Kabupaten Seluma berjumlah 35 lansia. Teknik pengambilan sampel secara Total Sampling. Pengumpulan data menggunakan data primer dan sekunder. Teknik analisis data menggunakan uji Chi-Square $\left(\chi^{2}\right)$. Hasil penelitian adalah dari 35 lansia terdapat 19 lansia (54,3\%) yang mendapatkan dukungan keluarga, 10 lansia (28,6\%) yang mengalami ketergantungan sedang, dan ada hubungan yang signifikan dukungan keluarga dengan kemandirian lansia di wilayah kerja Puskesmas Puguk Kabupaten Seluma dengan kategori hubungan erat. Diharapkan kepada Puskesmas dapat memberikan edukasi kepada keluarga agar dapat memberikan dukungan kepada lansia di Posbindu Cempaka wilayah kerja Puskesmas Puguk Kabupaten Seluma.
\end{abstract}

Kata Kunci : dukungan keluarga, kemandirian, lansia

\begin{abstract}
An increasing number of elderly people is happening now, causing various health problems in the elderly. The problems related to old age include the influence of the aging process which can cause various problems on physical, psychological and social changes. In general, physical changes will have an impact on decreasing the daily activities undertaken by the elderly. These physical changes will affect the level of independence of the elderly in their activities. The purpose of this study was to determine the relationship of family support with the
\end{abstract}


independence of the elderly in Posbindu Cempaka working area of Puguk Health Center, Seluma Regency. This research is an Analytical Survey research with Cross Sectional design. The population in this study were all elderly in Posbindu Cempaka, Puguk Village, Seluma Regency in June 2019, amounting to 35 elderly people. The sample in this study were all elderly who visited the Posbindu Cempaka working area of Puguk Health Center, Seluma Regency, amounting to 35 elderly. The sampling technique is Total Sampling. Data collection uses primary and secondary data. Data analysis techniques using the Chi-Square test $\left(\chi^{2}\right)$. The results of the study are that of the 35 elderly there are 19 elderly (54.3\%) who get family support, 10 elderly (28.6\%) who experience moderate dependence, and there is a significant relationship of family support with the independence of the elderly in the working area of Puguk Health Center, Seluma Regency with the category of close relations. It is expected that Health Center can provide education to families so that they can provide support to the elderly in Posbindu Cempaka working area of Puguk Health Center, Seluma Regency.

Keywords: family support, independence, elderly

\section{A. Pendahuluan}

Salah satu indikator dari suatu keberhasilan pembangunan nasional dilihat dari segi kesehatan adalah semakin meningkatnya usia harapan hidup penduduk. Berdasarkan sumber dari World Population Prospects tahun 2017, bahwa penduduk Indonesia antara tahun 2015-2020 memiliki proyeksi rata-rata usia harapan hidup sebesar 71,7 tahun. Meningkat 1\% dari tahun 2010-2015. Meningkatnya usia harapan hidup, dapat menyebabkan peningkatan jumlah lanjut usia (lansia) dari tahun ketahun (Kemenkes RI, 2017).

Peningkatan jumlah lansia yang terjadi kini, menimbulkan berbagai masalah kesehatan pada lansia. Adapun permasalahan yang terkait dengan lanjut usia antara lain pengaruh proses menua yang dapat menimbulkan berbagai masalah terhadap perubahan fisik, psikologi maupun sosial. Secara umum perubahan fisik akan berdampak pada penurunan aktivitas sehari-hari yang dijalani oleh lansia. Perubahan fisik tersebut akan mempengaruhi tingkat kemandirian lansia dalam beraktivitas (Rohaedi, Putri dan Karimah, 2016).

\begin{abstract}
Kemandirian merupakan kemampuan untuk memenuhi kebutuhan seseorang adalah tujuan paling penting pada sebagian besar lansia tanpa melihat status kesehatannya. Kemandirian memberikan mereka rasa kehormatan, kebanggaan dan berfungsinya diri sehingga tidak menjadi beban bagi orang lain (Wiraguna, 2014).
\end{abstract}

Bagi orang lanjut usia yang masih sehat, kemandirian dapat mempertahankan harga dirinya. Hal ini dapat meningkatkan kebahagian dalam dirinya (Indriana, 2012). Seperti yang dikemukakan dalam teori aktivitas bahwa lanjut usia akan merasakan kepuasan bila dapat melakukan aktivitas dan mempertahankan aktivitas tersebut selama mungkin. Ediawati (2012) menggambarkan lansia sebagai suatu unit yang juga menghendaki kemandirian dalam mempertahankan hidup, kesehatan dan kesejahteraannya.

Beberapa penghambat lansia dalam melakukan kegiatan aktivitas sehari-hari diantaranya kurangnya pengetahuan, dukungan keluarga dan motivasi (Aini, Arifianto \& Auliazardhi, 2017). Dukungan keluarga sangat penting dalam 
menunjang kemandirian lansia karena lansia beresiko jatuh dapat mengakibatkan trauma serius, seperti nyeri, kelumpuhan bahkan kematian. Hal ini menimbulkan rasa takut dan hilangnya rasa percaya diri sehingga lansia membatasi aktivitasnya seharihari (Af'idah, Dewi \& Hadhisuyatmana, 2019).

Penelitian Bandong, Haskas \& Akmal (2018) menunjukan bahwa ada hubungan dukungan keluarga dengan kemandirian lanjut usia dalam pemenuhan kebutuhan sehari-hari. Berdasarkan hasil analisis tersebut dapat dikatakan bahwa dukungan keluarga dapat memotivasi lansia untuk dapat mengelola kemandiriannya dalam beraktivitas.

Data Dinas Kesehatan Provinsi Bengkulu tahun 2017 didapatkan jumlah lansia yang memiliki umur 70 tahun keatas tertinggi yaitu Kabupaten Rejang Lebong (8909 orang), Kabupaten Seluma (7395 orang) dan Kabupaten Bengkulu Selatan (6799 orang). Selanjutnya, yang terendah yaitu Kabupaten Bengkulu Tengah (2070 orang), Kabupaten Muko-Muko (2619 orang) dan Kabupaten Lebong (3504 orang) (Dinkes Provinsi Bengkulu, 2018).

Data diatas menunjukkan bahwa Kabupaten Seluma menempati urutan kedua tertinggi lansia yang memiliki umur 70 tahun keatas yang lebih beresiko untuk mengalami hambatan dalam melakukan kegiatan sehari-hari. Data Dinas Kesehatan Kabupaten Seluma tahun 2017 Puskesmas Puguk merupakan Puskesmas yang terbanyak memiliki lansia yaitu sebanyak 179 orang.

Data register Posyandu

Puskesmas Puguk tahun 2018 didapatkan bahwa lansia yang tidak bisa beraktifitas secara mandiri sebanyak 22 lansia. Lansia yang tidak beraktifitas secara mandiri terdiri dari berjalan menggunakan bantuan tongkat sebanyak 15 orang, tidak bisa bangun dari tempat tidur sebanyak 7 orang (Puskesmas Puguk, 2018).

Survey awal tanggal 17 April 2019 di Posbindu Cempaka pada 5 orang lansia didapatkan bahwa 2 orang tidak mampu bergerak, BAB dan BAK di tempat tidur, tidak bisa mandi dan perawatan diri secara mandiri dan makan dibantu keluarga, 2 orang bergerak dengan alat bantu, BAB dan BAK, bisa mandi dan perawatan diri dibantu keluarga dan 1 orang orang mampu bergerak, BAB dan BAK di toilet, bisa mandi dan perawatan diri secara mandiri. Selanjutnya, 3 dari mereka mendapatkan dukungan keluarga (dibantu dan didampingi dalam melakukan kegiatan sehari-hari) dan 2 tidak mendapatkan dukungan keluarga (tidak semua dibantu dan didampingi) dalam menjalankan aktivitas sehari-hari.

\section{B. Metode Penelitian}

Penelitian ini dilaksanakan di wilayah kerja Puskesmas Puguk Kabupaten Seluma dilaksanakan pada bulan 23 Juli-23 Agustus 2019. Jenis penelitian yang digunakan adalah survey analitik dengan menggunakan rancangan penelitian cross Sectional. Populsai dalam penelitian ini adalah seluruh lansia di Posbindu Cempaka Wilayah Kerja Puskesmas Puguk Kabupaten Seluma bulan Juni tahun 2019 berjumlah 35 lansia. Teknik pengumpulan sampel dalam peneltian ini adalah total sampling. Pengumpulan data menggunakan data primer dan sekunder. Data dianalisis menggunakan analisis univariat dan analisis bivariat. Teknik analisis data menggunakan uji Chi-Square $\left(\chi^{2}\right)$. 


\section{Hasil Penelitian \\ 1. Analisis Univariat}

Analisis ini dilakukan untuk menggambarkan distribusi frekuensi tentang variabel independent (dukungan keluarga) dan variabel dependent (kemandirian lansia) di Wilayah Kerja Puskesmas Puguk Kabupaten Seluma. Hasil analisisnya yaitu sebagai berikut ini:

Tabel 1

Distribusi Frekuensi Dukungan Keluarga di Posbindu Cempaka Wilayah Kerja Puskesmas Puguk Kabupaten Seluma

\begin{tabular}{clcc}
\hline No & Dukungan Keluarga & Frekuensi & Persentase $(\%)$ \\
\hline 1 & Tidak Mendukung & 16 & 45,7 \\
2 & Mendukung & 19 & 54,3 \\
\hline \multicolumn{2}{l}{ Total } & 35 & 100,0 \\
\hline
\end{tabular}

Berdasarkan Tabel 1 dapat mengatakan keluarga mendukung di diketahui bahwa dari 35 lansia terdapat, Posbindu Cempaka Wilayah Kerja 16 lansia yang tidak mendapatkan Puskesmas Puguk Kabupaten Seluma. dukungan keluarga dan 19 lansia yang

Tabel 2

Distribusi Frekuensi Kemandirian Lansia di Posbindu Cempaka Wilayah Kerja Puskesmas Puguk Kabupaten Seluma

\begin{tabular}{clcc}
\hline No & \multicolumn{1}{c}{ Kemandirian Lansia } & Frekuensi & Persentase (\%) \\
\hline 1 & Ketergantungan total & 3 & 8,6 \\
2 & Ketergantungan berat & 5 & 14,2 \\
3 & Ketergantungan sedang & 10 & 28,6 \\
4 & Ketergantungan ringan & 9 & 25,7 \\
5 & Mandiri & 8 & 22,9 \\
\hline & Total & 35 & 100,0 \\
\hline
\end{tabular}

Berdasarkan Tabel 2 dapat diketahui bahwa dari 35 lansia terdapat 3 lansia dengan ketergantungan total, 5 lansia dengan ketergantungan berat, 10 lansia dengan ketergantungan sedang, 9 lansia dengan ketergantungan ringan dan 8 lansia mandiri di Posbindu Cempaka Wilayah Kerja Puskesmas Puguk Kabupaten Seluma.

\section{Analisis Bivariat}

Analisis bivariat dilakukan untuk mengetahui hubungan dukungan keluarga dengan kemandirian lansia di Posbindu Cempaka Wilayah Kerja Puskesmas Puguk Kabupaten Seluma Hasil analisis bivariat kedua variabel tersebut dapat dilihat sebagai berikut: 
Tabel 3

Hubungan Dukungan Keluarga dengan Kemandirian Lansia di Posbindu Cempaka Wilayah Kerja Puskesmas Puguk Kabupaten Seluma

\begin{tabular}{|c|c|c|c|c|c|c|c|c|c|c|c|c|c|c|c|}
\hline \multirow{3}{*}{$\begin{array}{c}\text { Dukungan } \\
\text { Keluarga }\end{array}$} & \multicolumn{10}{|c|}{ Kemandirian Lansia } & \multirow{2}{*}{\multicolumn{2}{|c|}{ Total }} & \multirow{3}{*}{$\chi^{2}$} & \multirow{3}{*}{$\mathrm{p}$} & \multirow{3}{*}{$\mathrm{C}$} \\
\hline & & $\begin{array}{l}\text { ter } \\
\text { ntu } \\
\text { an } \\
\text { tal }\end{array}$ & & $\begin{array}{l}\text { eter } \\
\text { ntu } \\
\text { gan } \\
\text { rat }\end{array}$ & & $\begin{array}{l}\text { ter } \\
\text { ntu } \\
\text { an } \\
\text { lang }\end{array}$ & & $\begin{array}{l}\text { eter } \\
\text { Intu } \\
\text { gan } \\
\text { gan }\end{array}$ & \multicolumn{2}{|c|}{ Mandiri } & & & & & \\
\hline & $\mathrm{F}$ & $\%$ & $\mathrm{f}$ & $\%$ & $\mathrm{f}$ & $\%$ & $\mathrm{f}$ & $\%$ & $\mathrm{~F}$ & $\%$ & $f$ & $\%$ & & & \\
\hline $\begin{array}{l}\text { Tidak } \\
\text { Mendukung }\end{array}$ & 3 & 18,8 & 4 & 25,0 & 7 & 43,8 & 1 & 6,3 & 1 & 6,3 & 16 & 100 & & & \\
\hline Mendukung & 0 & 0 & 1 & 5,3 & 3 & 15,8 & 8 & 42,1 & 7 & 36,8 & 19 & 100 & 0,20 & 0,003 & 0,563 \\
\hline Total & 3 & 8,6 & 5 & 14,3 & 10 & 28,6 & 9 & 25,7 & 8 & 22,9 & 35 & 100 & & & \\
\hline
\end{tabular}

Tabel 3 menggambarkan hasil tabulasi silang antara dukungan keluarga dengan kemandirian lansia di Posbindu Cempaka Wilayah Kerja Puskesmas Puguk Kabupaten Seluma. Dari 16 keluarga tidak mendukung, terdapat 3 lansia dengan ketergantungan total, 4 lansia dengan ketergantungan berat, 7 lansia dengan ketergantungan sedang, 1 lansia dengan ketergantungan ringan dan 1 lansia mandiri. Dari 19 lansia yang mendapat dukungan keluarga, tidak ada yang mengalami ketergantungan total, 1 lansia dengan ketergantungan berat, 3 lansia dengan ketergantungan sedang, 8 lansia dengan ketergantungan ringan, dan 7 lansia mandiri.

Untuk mengetahui hubungan antara dukungan keluarga dengan kemandirian lansia di Posbindu Cempaka wilayah kerja Puskesmas Puguk Kabupaten Seluma digunakan Uji Chi-Square (Pearson Chi-Square). Hasil Uji Pearson Chi-Square diperoleh nilai $\chi^{2}=16,206$ dengan nilai $\mathrm{p}$ (Asymp.Sig. $)=0,003$, karena nilai $\mathrm{p}<0,05$ berarti signifikan, maka Ho ditolak Ha diterima, artinya terdapat hubungan yang signifikan dukungan keluarga dengan kemandirian lansia di Posbindu Cempaka Wilayah Kerja Puskesmas Puguk Kabupaten Seluma.
Untuk mengetahui keeratan hubungan antara dukungan keluarga dengan kemandirian lansia di Posbindu Cempaka Wilayah Kerja Puskesmas Puguk Kabupaten Seluma digunakan Uji Contingency Coefficient didapat nilai $\mathrm{C}=0,563$ dengan nilai $\mathrm{p}=0,003<0,05$ berarti signifikan, nilai $\mathrm{C}$ $=0,563$ dibandingkan dengan nilai $\mathrm{C}_{\max }$ $=0,707$. Jadi nilai $\frac{C}{C_{\max }}=\frac{0,563}{0,707}=0,796$ karena nilai ini terletak dalam interval 0,60-0,80 maka kategori hubungan erat.

\section{Pembahasan}

Berdasarkan hasil analisis univariat tentang dukungan keluarga diketahui bahwa dari 35 lansia terdapat 16 lansia yang tidak mendapatkan dukungan keluarga karena lansia tersebut tidak tinggal bersama anggota keluarga atau tinggal sendiri. Hal ini terlihat dari hasil kuesioner yang menyatakan bahwa keluarga lansia hanya kadang-kadang saja untuk mengingatkan lansia tentang berhatihati dalam melakukan kegiatan/ aktivitas sehari-hari, tidak pernah mengingatkan untuk menjaga kebersihan kemaluan sehabis buang air besar atau buang air kecil, tidak pernah mengingatkan untuk memeriksa kesehatan secara teratur ke pos pelayanan kesehatan, tidak pernah 
memberi nasehat untuk selalu mengusahakan tempat tidur lansia selalu dalam keadaan bersih, tidak pernah memberikan hasil pujian terhadap hasil kerja yang telah dilakukan oleh lansia seperti memasak dan mencuci serta juga tidak pernah memberikan pujian jika lansia senang mengikuti kegiatan diluar rumah. Selain itu tidak adanya dukungan dari keluarga juga terlihat dari lansia yang jarang menyediakan waktu untuk menemani lansia, jarang menyiapkan dan mengatur jenis-jenis makanan secara khusus untuk lansia, dan tidak berusaha untuk mencarikan kekurangan sarana yang diperlukan oleh lansia serta kelurga kurang bersabar dalam mendengarkan keluhan dari lansia.

Dari 35 lansia, terdapat 19 lansia yang mendapatkan dukungan keluarga. Hal ini terlihat dari hasil kuesioner yang menyatakan bahwa kelurga selalu menjaga dan memantau aktivitas yang dilakukan oleh lansia dalam kesehariannya seperti, keluarga selalu mengontrol kegiatan, mandi dan makan secara rutin kepada lansia, selalu mengingatkan tentang kebersihan sehabis dari buang air besar atapun buang air kecil demi menjaga kesehatan lansia, keluarga selalu merawat lansia dengan penuh kasih sayang, selalu sabar mendengarkan keluhan dari lansia, selalu berusaha untuk memenuhi sarana yang diperlukan lansia serta selalu memberi nasehat dan menyiapkan makanan yang bergizi/baik bagi kesehatan lansia.

Hasil penelitian ini sesuai dengan penelitian yang dilakukan oleh Mirza (2017) yang menyatakan bahwa dukungan keluarga merupakan sikap, tindakan dan penerimaan keluarga terhadap penderita yang sakit berasal dari orang lain (orangtua, anak, suami, istri atau saudara) yang dekat dengan penderita, dimana bentuk dukungan dapat berupa informasi, tingkah laku tertentu atau materi yang dapat menjadikan individu merasa disayangi, diperhatikan dan dicintai.

Berdasarkan hasil analisis univariat tentang kemandirian lansia diketahui bahwa dari 35 lansia terdapat 3 lansia dengan ketergantungan total yang tinggal bersama anggota keluarga. Hal ini terlihat dari hasil kuesioner dan observasi yang menyatakan jika lansia ini sudah bedrest total dan segala kebutuhan dan aktivitas sehari-harinya dibantu sepenuhnya oleh keluarga karena lansia tersebut menderita penyakit stroke, gagal ginjal kronik dan patah kaki karena kecelakaan. Selanjutnya terdapat 5 lansia dengan ketergantungan berat karena sebagian besar aktivitas sehari-hari lansia tersebut banyak dibantu oleh anggota keluarga yang tinggal bersama lansia, hal ini terlihat dari lansia yang menyatakan bahwa sebagian besar kebutuhan dan aktivitas sehari-harinya dibantu oleh keluarga, hanya makan, perawatan diri berpakaian dan buang air kecil yang tidak dibantu oleh keluarga.

Kemudian terdapat 10 lansia dengan ketergantungan sedang. Hal ini dapat dilihat dari hasil kuesioner yang menyatakan jika lansia dalam melakukan aktivitas dan kegiatan sehari-harinya banyak dibantu oleh keluarga, seperti ketika berjalan dan naik turun tangga harus dibantu oleh keluarga demikian halnya ketika mandi dan dalam penggunaan toilet serta buang air besar supaya bersih harus dibantu oleh keluarga.

Sementara itu terdapat 9 lansia dengan ketergantungan ringan. Hal ini terlihat dari hasil kuesioner bahwa lansia menyatakan hanya saat melakukan aktivitas yang cukup berat mereka harus dibantu oleh keluarga seperti ketika naik turun tangga mereka 
membutuhkan alat bantu agar bisa naik turun tangga dengan baik. Ada 8 lansia dengan usia rentang 58-61 tahun yang masih bisa mandiri. Hal ini terlihat dari jawaban lansia yang menyatakan kalau lansia dalam kesehariannya masih bisa melakukan semua aktivitas yang ada tanpa bantuan dari keluarga dan tidak ada penyakit kronik yang diderita oleh lansia tersebut.

Hasil penelitian ini sesuai dengan penelitian yang dilakukan oleh Sari (2013), yang menyimpulakn bahwa kemandirian lansia dalam Activity of Dayly Living (ADL) merupakan kemandirian seseorang dalam melakukan aktivitas dan fungsi kehidupan harian yang dilakukan oleh lansia secara rutin dan universal.

Berdasarkan analisis bivariat diketahui bahwa dari 16 lansia yang keluarganya tidak mendukung. Tidak ada dukungan keluarga ini karena anggota keluarganya tidak dapat membantu secara langsung lansia untuk memenuhi kebutuhannya sehari-hari, dikarenakan anak lansia tersebut tinggal di Kota yang berbeda dengan lansia (tinggal tidak bersama anggota keluarga). Dari lansia yang keluarganya tidak mendukung terdapat 3 lansia dengan ketergantungan total. Hal ini dikarenakan lansia memang sudah tidak mampu lagi melakukan semua aktivitasnya sehari-hari tanpa bantuan dari keluarga (bedrest total), 1 lansia mengalami sakit stroke, 1 lansia mengalami penyakit gagal ginjal kronik dan 1 lansia kakinya diamputasi karena kecelakaan kerja, walaupun tidak ada dukungan keluarga secara langsung untuk dapat membantu lansia dalam melakukan kegiatannya sehari-hari, keluarga lansia ini membayar jasa orang lain untuk membantu lansia dalam memenuhi kebutuhan pribadinya sehari-hari.
Dari dukungan keluarga yang tidak mendukung, terdapat 4 lansia dengan ketergantungan berat. Diantara lansia tersebut ada yang mengalami vertigo, hipertensi, katarak dan asam urat. Hal ini karena lansia sebagian besar sudah tidak mampu lagi untuk melakukan aktivitas walaupun aktivitas itu ringan tanpa bantuan dari keluarga, seperti sudah tidak bisa lagi menggunting kuku sendiri, harus dibantu saat memakai pakaian, harus di bantu saat mandi supaya bersih serta dalam bersisir atau merapikan rambutpun sudah harus dibantu.

Kemudian dari keluarga yang tidak mendukung, terdapat 7 lansia dengan ketergantungan sedang. Hal ini karena ada dari aktivitas sehari-hari yang sudah tidak bisa lagi dilakukan oleh lansia seperti pada saat menggunakan toilet harus sedikit dibantu dan di cucikan setelah baung air besar supaya bersih, serta terdapat 1 orang dengan ketergantungan ringan, hal ini karena lansia masih banyak yang bisa melakukan aktivitas sehari hari tanpa bantuan dari keluarga, hanya saja ada aktiviatas yang cukup berat yang sudah tidak bisa dilakukannya sendiri seperti harus dengan bantuan menggunakan alat (tongkat) supaya tetap seimbang dan dapat naik tangga dengan baik.

Ada 1 lansia yang tidak mendapat dukungan keluarga dan lansia tersebut mandiri. Berdasarkan wawancara dan observasi dengan lansia tersebut, lansia tersebut tidak memiliki penyakit berat, fisik terlihat kuat dan segar, ikut terlibat sebagai pengurus di kelompok tani (kebun kopi) dan masjid.

Selanjutnya dari tabel 3 , terdapat 19 lansia yang keluarganya mendukung. Dukungan keluarga terhadap lansia ini seperti keluarga selalu ada yang menemani/mengurus lansia dalam melakukan kegiatannya 
sehari-hari. Dari 19 lansia yang keluarganya mendukung, terdapat 1 lansia yang kemandirian lansia dengan ketergantungannya berat. Berdasarkan wawancara dan observasi, lansia tersebut menderita penyakit diabetes mellitus, yang sudah menahun dan berat, status gizinya kurang, tidak pernah mengikuti pendidikan sekolah, dan kehidupannya bergantung kepada keluarganya (sudah tidak bekerja lagi). Hal ini karena lansia tidak mampu lagi untuk melakukan aktivitas walaupun aktivitas itu ringan tanpa bantuan dari keluarga, seperti harus dibantu saat memakai pakaian dan saat mandi, dan tidak bisa lagi menggunting kuku sendiri serta dalam bersisir atau merapikan rambut sudah harus dibantu.

Selain itu terdapat 3 lansia yang kemandirian lansia dengan ketergantungannya sedang, hal ini karena walaupun keluarganya mendukung namun lansia tersebut masih merasa mampu untuk melakukan beberapa aktivitas sehari-hari tanpa bantuan dari kelurga seperti makan sendiri, mandi sendiri, berpakaian sendiri, memotong kuku sendiri serta masih bisa melakukan perawatan diri dan mencuci sehabis buang air besar sendiri tanpa bantuan dari orang lain. berdasarkan hasil wawancara dan observasi terhadap lansia tersebut, ada 1 lansia yang mengalami gangguan penglihatan, 1 lansia menderita penyakit hipertensi, (tekanan darah 180/120) dan 1 lansia menderita penyakit vertigo. 2 lansia bekerja di kebun dan 1 orang sudah tidak bekerja dan berpendidikan dasar (SD).

Selanjutnya terdapat 8 orang lansia dengan ketergantungan ringan, hal ini dapat dijelaskan karena lansia merasa masih amat sangat kuat dan mampu untuk melakukan semua aktivitas sehari-hari dan tidak mau untuk meminta bantuan kepada keluarga kecuali hanya aktivitas yang cukup berat dan berbahaya jika dilakukan tanpa bantuan keluarga seperti naik turun tangga, berdasarkan wawancara dan observasi, beberapa lansia mengalami penyakit asam urat, rematik, gastritis kronik, ada 6 lansia yang masih bekerja dan 2 lansia sudah tidak bekerja lagi. Ada 7 lansia yang mandiri. Hal ini walaupun keluarga sangat ingin membantu lansia dalam melakukan aktivitas sehari-hari, namun lansia tetap melakukannnya sendiri tanpa bantuan dari keluarga karena merasa masih sangat mampu dan sehat untuk melakukannya sendiri.

Berdasarkan hasil analisis bivariat dengan menggunakan uji Pearson Chi-Square, diketahui ada hubungan yang signifikan antara dukungan keluarga dengan kemandirian lansia di Posbindu Cempaka Wilayah Kerja Puskesmas Puguk Kabupaten Seluma, artinya semakin baik dukungan keluarga, maka semakin besar kemungkinan kemandirian lansia dan sebaliknya semakin kurang dukungan maka kemungkinan semakin tidak baik kemandirian lansia di Posbindu Cempaka wilayah kerja Puskesmas Puguk Kabupaten Seluma.

Selanjutnya dari hasil uji contingency coefficient diketahui keeratan hubungan dukungan keluarga dengan kemandirian lansia di Posbindu Cempaka wilayah kerja Puskesmas Puguk Kabupaten Seluma dengan kategori erat, artinya dukungan keluarga merupakan salah satu faktor penentu adanya kemandirian lansia di Posbindu Cempaka wilayah kerja Puskesmas Puguk Kabupaten Seluma.

Hasil penelitian ini sejalan dengan penelitian yang dilakukan oleh Felpina, Wiyono \& Maryah (2016) yang menyatakan ada hubungan yang signifikan antara dukungan keluarga 
dengan kemandirian lansia di Posyandu Permadi RW 02 Tlogomas kota Malang Tahun 2015.

Berdasarkan hasil penelitian dan pembahasan yang sudah diuraikan diatas maka peneliti mengambil kesimpulan bahwa dukungan keluarga sangat diperlukan bagi lansia, dengan cara ada anggota keluarga yang tinggal bersama lansia, terutama bagi lansia dengan ketergantungan total (bedrest total) yang disebabkan oleh penyakit stroke, gagal ginjal kronik, patah kaki karena kecelakaan yang semuanya tidak memungkinkan lagi bagi lansia untuk melakukan aktivitasnya seharihari tanpa bantuan dari keluarga.

Demikian juga halnya dengan lansia yang ketergantungan ringan, sebaiknya harus tetap ditemani oleh keluarga agar dapat membantu lansia dalam menjalankan aktivitas atau kegiatannya sehari-hari, terutama aktivitas yang dapat membahayakan lansia seperti naik turun tangga, berjalan keluar rumah, mandi dan penggunaan toilet. Selain itu lansia juga membutuhkan keluarga untuk menjadi teman bercerita sehingga lansia tidak merasa stres sendiri, tetapi lansia merasa senang karena diperhatikan dan disayangi sepenuhnya oleh kelaurga. Keluarga juga berperan dalam menjaga kesehatan lansia dengan cara memperhatikan pola makan ataupun asupan gizi yang dikonsumsi oleh lansia yang tidak bisa disiapkan sendiri lagi oleh lansia. Untuk itulah lansia sangat membutuhkan dukungan keluarga dan harus tinggal bersama anggota keluarga untuk membantu melakukan aktivitasnya dalam kehidupan sehari-hari.

\section{E. Kesimpulan}

1. Dari 35 lansia terdapat 19 orang $(54,3 \%)$ yang mendapat dukungan keluarga di Posbindu Cempaka
Wilayah Kerja Puskesmas Puguk Kabupaten Seluma.

2. Dari 35 lansia terdapat 10 orang $(28,6 \%)$ yang mengalami ketergantungan sedang di Posbindu Cempaka Wilayah Kerja Puskesmas Puguk Kabupaten Seluma.

3. Terdapat hubungan yang signifikan dukungan keluarga dengan kemandirian lansia di Wilayah Kerja Puskesmas Puguk Kabupaten Seluma dengan kategori hubungan erat.

\section{Daftar Pustaka}

Af'idah, Dewi, Y.S \& Hadhisuyatmana, S. (2019). Studi Risiko Jatuh Melalui Pemeriksaan Dynamic Gait Index (DGI) Pada Lansia Di Panti Werdha Hargodedali Surabaya. Naskah Publikasi. Fakultas Keperawatan Universitas Airlangga.

Aini, Arifianto \& Auliazardhi, Y. (2014). Faktor-Faktor yang Berhubungan dengan Kemandirian Activity of Daily Living (ADL) pada Pasien Post Stroke di Rehabilitasi Medik RSUD Tugurejo Semarang. Naskah Publikasi. Program Studi Ners STIKES Widya Husada Semarang.

Bandong, Haskas, Y \& Akmal. (2018). Hubungan Dukungan Keluarga dengan Kemandirian Lanjut Usia dalam Pemenuhan Kebutuhan Sehari-Hari di Wilayah Kerja Puskesmas Batua Makassar. Jurnal Ilmiah Kesehatan Diagnosis 12 (5):7074.

Dinkes Provinsi Bengkulu. (2018). Profil Kesehatan Provinsi Bengkulu Tahun 2017. Dinas Kesehatan Provinsi Bengkulu. 
Ediawati, E. (2012). Gambaran Tingkat Kemandirian dalam Activity Daily Of Living (ADL) dan Resiko Jatuh Pada Lansia Di Panti Sosial Tresna Wredha Budi Mulia 01 Dan 03 Jakarta Timur. Skripsi. Program Sarjana Ilmu Keperawatan Fakultas Ilmu Keperawatan Universitas Indonesia.

Felpina, Wiyono, $\mathrm{K} \&$ Maryah, V. (2017). Hubungan Dukungan Keluarga dengan Kemandirian Lansia dalam Pemenuhan ADL di Kelurahan Tlogomas Kota Malang. Nursing News 1(2): 101-114. Diakses dari https://publikasi.unitri.ac.id/inde x.php/fikes/article/view/428/346

Indriana, Y. (2012). Gerontologi dan Progeria. Yogyakarta: Pustaka Pelajar.

Kemenkes RI. (2016). Situasi dan Analisis Lanjut Usia dan Gambaran Kesehatan Lanjut Usia di Indonesia. Kementerian Kesehatan. Jakarta.

Kemenkes RI. (2017). Situasi dan Analisis Lanjut Usia dan Gambaran Kesehatan Lanjut Usia di Indonesia. Kementerian Kesehatan. Jakarta.

Mirza. (2017). Memaksimalkan Dukungan Keluarga Guna Meningkatkan Kualitas Hidup Pasien Diabetes Mellitus. Jurnal JUMANTIK 2(2): 12-30. Diakses dari http://jurnal.uinsu.ac.id/index.p hp/kesmas/article/view/1122/88 $\underline{8}$

Puskesmas Puguk. (2018). Profil Puskesmas Puguk 2017. Puskesmas Puguk Kabupaten Seluma

Rohaedi, Putri, S.C \& Karimah, A.D. (2016). Tingkat Kemandirian Lansia dalam Activities Daily
Living di Panti Sosial Tresna Werdha Senja Rawi. Jurnal Pendidikan Keperawatan Indonesia 2(1): 16-21. Diakses dari

https://ejournal.upi.edu/index.p hp/JPKI/article/download/2848/ $\underline{1883}$

Sari. (2013). Gambaran Tingkat Kemandirian Lansia Di Dusun Blimbing Desa Sukorejo Kecamatan Sukorejo Kabupaten Ponorogo.Skripsi. Universitas Muhammadiyah Ponorogo.

Wiraguna. (2014). Gambaran Tingkat Kemandirian dalam Activities Daily Living (ADL) pada Lansia di Desa Leyangan Kecamatan Ungaran Timur Kabupaten Semarang. Skripsi. Program Studi Ilmu Keperawatan Stikes Ngudi Waluyo Ungaran. 